\title{
Inhibition of quorum sensing virulente factors of Pseudomonas aeruginosa PAO1 by Ferulago macedonica and Echinophora sibthorpiana extracts and essential oils
}

\author{
Ksenija Mileski ${ }^{1, *}$, Ana Ćırıć ${ }^{2}$, Vlado Matevski ${ }^{3,4}$, Petar Marin ${ }^{1}$, Marina Soković ${ }^{2}$, And \\ ANA DŽAMIĆ ${ }^{1}$ \\ ${ }^{1}$ Institute of Botany and Botanical Garden "Jevremovac", Faculty of Biology, University of Belgrade, Studentski trg 16, 11000 Belgrade, Serbia \\ ${ }^{2}$ Dep. of Plant Physiology, Institute for Biological Research "Siniša Stanković", University of Belgrade, Bul. Despota Stefana, 142,11000 Belgrade, Serbia \\ ${ }^{3}$ Institute of Biology, Faculty of Natural Sciences and Mathematics, University "S. Kiril and Metodij", Gazi Baba, 1000 Skopje, Macedonia \\ ${ }^{4}$ Macedonian Academy of Sciences and Arts, Bul. Krste Misirkov, 2, P.O. Box 428, 1000 Skopje, Macedonia \\ *Corresponding author: ksenija.mileski@bio.bg.ac.rs
}

Received: December 8, 2017

Accepted: December 13, 2017

Published on-line: December 14, 2017

Published: December 25, 2017

\begin{abstract}
This study was conducted to analyse extracts and essential oils of Ferulago macedonica and Echinophora sibthorpiana (Apiaceae) for anti-quorum sensing potential using Pseudomonas aerugonisa PAO1 as biomonitoring system. Anti-quorum sensing screening was carried out by tree different tests which showed that examined samples possessed significant effects in suppressing of some virulent determinants of PAO1. The essential oils of $F$. macedonica and E. sibthorpiana aerial parts reduced the growth and modified the appearance of $P$. aeruginosa colonies and flagella to a large extent in twitching and motility assay. In the presence of essential oil of E. sibthorpiana, diameter of the colony was $6.67 \mathrm{~mm}$, the flagella were absent and the color of the colony was changed from green to white. In anti-biofilm assay, the inhibitory activity of $E$. sibthorpiana was more notable than of F. macedonica. Applied colorimetric test revealed that examined samples strongly reduced the production of pigment pyocyanin where the highest inhibition of its synthesis showed $F$. macedonica oil $(5.22 \%)$, followed by E. sibthorpiana oil $(10.69 \%)$, which was singnificantly higher potential in comparison to used antibiotics $(84.27 \%$ and $97.59 \%$ for streptomycin and ampicillin, respectively).
\end{abstract}

Key words: Apiaceae, Ferulago macedonica, Echinophora sibthorpiana, anti-quorum sensing, Pseudomonas aeruginosa PAO1

\section{INTRODUCTION}

Studied species Ferulago macedonica Micevski et Mayer and Echinophora sibthorpiana (Guss.) Tutin are herbaceous perennial plants which belong to the carrot family (Apiaceae). Endemic F. macedonica, with upright stem and yellow inflorescence, can be found in a limestone area of Republic of Macedonia. It belongs to the genus Ferulago W. Koch which includes around 50 species spread in Iran, Turkestan and in surrounding of Adriatic Sea (Canonn, 1968). Genus Echinophora L. consists of species E. tenuifolia L. and E. spinosa L. which are distributed from Mediteranian region to Crete and Crimea. In flora Europaea it is recorded that species E. tenuifolia consists of subsp. tenuifolia and subsp. sibthorpiana (Tutin, 1968). According to recent data, E. tenuifolia subsp. sibthorpiana is treated as separate species E. sibthorpiana (Micevski, 2005). This species has strong roots, hairy leafs, branched stem and yellow inflorescence. It inhabits the mountain meadows and saline areas of Republic of Macedonia (Micevski, 2005).

Many Apiaceae species are known as aromatic and medicinal plants with wide usage in human diet, as well as in traditional and official medicine. Some species of Ferulago and Echinophora genera are utilized since ancient times as a flavoring and digestive agents. Thus, certain Ferulago species are added as spices to dishes or to melted fats for aromatization and as food preservatives. A few representatives of this taxa are used in traditional medicine as sedatives, tonics and in the treatment of intestinal wounds due to their antiparasitic effect. Moreover, they are used against ulcers, snake bites, headache and diseases of the spleen (Khalighi-Sigaroodi et al., 2005). In Turkey and Iran, extracts of the roots of Ferulago species are applied as aphrodisiacs. Also, their fragrance is used in the perfumery and cosmetic industry (Taran et al., 2010). Tarana 
herb which is local name for E. sibthorpiana in Turkey gives pleasant aroma and flavor in preparation of tarana-one of the oldest traditional Turkish dishes made of cereals. It was proven that this species stimulates the fermentation of tarana by affecting lactic acid bacteria and yeast Saccharomyces cerevisiae. In traditional medicine, it is used as a fungicide for the treatment of wounds and stomach ulcers, also, as digestive and anti-spasm agent (Baser et al., 1998; Cakilcioglu and Turkoglu, 2010; Değirmencioğlu et al., 2005; Gurbuz et al., 2010; Ozdemir et al., 2007). In addition, the seeds and the roots of this taxon have been effectively applied in the treatment of epilepsy (Eadie, 2004).

Previous studies on chemical analyses of F. macedonica and E. sibthorpiana showed that they possess various secondary metabolites. Thus, the chemical composition of Ferulago species revealed that they contain coumarins, polyacetylenes, flavonoids, monoterpenes, sesquiterpenes and aromatic compounds such as phenylpropanoids (Demirci and Özkan, 2014 Razavi et al., 2015; Ruberto et al., 1994). Regarding chemical analyses of Echinophora species, essential oils were studied most frequently. In essential oil of aerial parts of $E$. sibthorpiana, $\alpha$-phellandrene and methyl-eugenole were the most abundant components (Ahmad et al., 1999; Baser et al., 1994; 1998; Gokbulut et al., 2013). In extracts obtained from aerial parts of E. platyloba, stigmasterol, sitosterol, and stigmasterol- $\beta-\mathrm{D}-$ glycoside were identified as dominant constituents (Valizadeh et al., 2014). In regard to the complex chemical composition, Ferulago species exhibit numerous biological activities. The antimicrobial aspect of essential oils of Ferulago species was examined in few previous works (Cecchini et al., 2010; Ozkan et al., 2008; Taran et al., 2010). Essential oil of F. campestris showed to be a promising anti-Candida agent with extremely strong activity on clinically isolated strains of C. albicans, C. tropicans, and C. glabrata, thus corroborating the historical usage of this plant in the treatment of candidiasis (Cecchini et al., 2010). The various extracts and essential oils of Echinophora species in vitro also showed diverse biological activities and the most prominent were their antioxidant (Gholivand et al., 2011; Gokbulut et al., 2013; SaeiDehkordi et al., 2012) and antimicrobial potentials (Avijgan et al., 2010; 2012; Delaram et al., 2011; Entezari et al., 2009; Sharafati-chaleshtori et al., 2012; Youse et al., 2012). Moreover, it was found that flower, leaf, and stem essential oils from Echinophora lamondiana and from aerial parts of Echinophora tenuifolia ssp. sibthorpiana act as biopesticides and repellents (Ali et al., 2015; Evergetis et al., 2013).

This work represents the extension of our previous research, where F. macedonica and E. sibthorpiana were characterized for chemical profiles of essential oils and extracts. The most abundant compounds in essential oils of $F$. macedonica inflorescence and aerial parts were $\alpha$-pinene $(43.1 \%$ and $22.8 \%$, respectively) and sabinene (26.7\% and $15.5 \%$, respectively), while total phenolic and flavonoid contents in all extracts ranged between 34.12-59.68 mg GAE/g dw and 9.1-23.7 $\mathrm{mg} \mathrm{QE} / \mathrm{g}$ $\mathrm{dw}$, respectively (Mileski et al., 2015). In the essential oil of E. sibthorpiana methyl eugenol (60.4\%), p-cymene (11.2\%) and $\alpha$-phellandrene $(10.2 \%)$ were main compounds, while total phenolic and flavonoid concentrations in the extracts ranged from 38.6-60.7 mg GAE/g dw, and 3.1-19.0 mg QE/g dw, respectively (Mileski et al., 2014). The aim of this study was to determine the anti-quorum sensing (anti-QS) activity of $F$. macedonica and E. sibthorpiana on P. aeruginosa PAO1 taking into consideration the widespread use of related representatives as antimicrobial agents in traditional medicine. This analysis was conducted by determining the ability of extracts and essential oils to reduce twitching and flagella motility, biofilm formation and pyocyanin production of this bacterium and the comparison of their activity with the effects of commercial antibiotics was done.

\section{MATERIALS AND METHODS}

\section{Chemicals}

For antimicrobial assays, several solvents, culture broth, and standards were used. Organic solvents were purchased from "Zorka pharma", Šabac, Serbia. Tryptic Soy Broth (TSB) was obtained from the Institute of Immunology and Virology „Torlak", Belgrade, Serbia, while streptomycin and ampicillin solutions (1 mg/mL) from Hyclone, Logan, Ut, USA. Dimethylsulfoxide (DMSO) was purchased from Merck KGaA, Germany and phosphate-buffered saline (PBS) were from Sigma Chemical Co., St. Louis, USA.

\section{Plant Material}

Both species were collected in flowering stage at their natural sites of the Republic of Macedonia and determined by one of the authors, Prof. V. S. Matevski. Plant material of $F$. macedonica was collected around the Negotino city (GPS: N $41^{\circ} 30,362^{\prime}$, E $22^{\circ} 06,091^{\prime}$ ), while E. sibthorpiana was collected around the Štip city (GPS: N 41 ${ }^{\circ} 50,324^{\prime}$; E $22^{\circ} 08,289^{\prime}$ ) in July 2012. Voucher specimens of F. macedonica (BEOU 16659) and E. sibthorpiana (BEOU 16658) are deposited at the Herbarium of the Institute of Botany and Botanical Garden "Jevremovac", (BEOU), Faculty of Biology, University of Belgrade, Serbia.

\section{Plant extraction}

Methanol, ethanol and aqueous extracts of F. macedonica (inflorescence and aerial parts) and E. sibthorpiana (aerial parts and roots) were obtained by ultrasonic extraction procedure. Powdered plant materials ( $10 \mathrm{~g})$ were extracted for $24 \mathrm{~h}$ in the dark with $200 \mathrm{~mL}$ of listed solvents using an ultrasonic apparatus for the first and the last hour of extraction. After filtration, methanol and ethanol were evaporated under reduced pressure at $40^{\circ} \mathrm{C}$, while frozen aqueous were lyophilized. Measured extracts (Table 1 ) were kept in the glass bottles at $4^{\circ} \mathrm{C}$ until further application.

Table 1. Obtained yields of Ferulago macedonica and Echinophora sibthorpiana crude extracts.

\begin{tabular}{lllr}
\hline Species & Extract & Plant part & Yield [g] \\
\hline F. macedonica & Methanol & Inflorescence & 3.751 \\
& & Aerial parts & 1.332 \\
& \multirow{2}{*}{ Ethanol } & Inflorescence & 2.157 \\
& & Aerial parts & 1.179 \\
& \multirow{2}{*}{ Aqueous } & Inflorescence & 2.020 \\
& & Aerial parts & 1.351 \\
\hline \multirow{2}{*}{ E. sibthorpiana } & \multirow{2}{*}{ Methanol } & Aerial parts & 0.841 \\
& & Roots & 1.049 \\
& \multirow{2}{*}{ Ethanol } & Aerial parts & 0.794 \\
& \multirow{2}{*}{ Aqueous } & Roots & 0.482 \\
& & Aerial parts & 0.974 \\
& & Roots & 1.284 \\
\hline
\end{tabular}

\section{Essential oil isolation}

Yellowish essential oils of F. macedonica and E. sibthorpiana were isolated by hydrodistilation (3h) from $200 \mathrm{~g}$ of dry plant material using Clevenger apparatus (Ph.Eur.8.0., 2013). Obtained essential oils from aerial parts of F. macedonica (without inflorescence) and herbal parts of E. sibthorpiana (the whole plant) were refrigerated in a sealed vial prior to anti-QS analyses ( $0.61 \%$ and $0.43 \%, \mathrm{w} / \mathrm{w}$-dry bases, respectively). 


\section{Determination of anti-QS activity}

\subsection{Preparation of extracts}

Crude extracts of studied species were dissolved in 5\% DMSO to obtain the stock concentrations of $20 \mathrm{mg} / \mathrm{mL}$ for F. macedonica and $30 \mathrm{mg} / \mathrm{mL}$ for E. sibthorpiana samples. Subsequently, obtained solutions were diluted in appropriate ratio for further analyses.

\subsection{Bacterial strain, growth media and culture conditions}

The bacterium Pseudomonas aeruginosa PAO1 from Institute for Biological Research "Siniša Stanković" in Belgrade, Serbia was used to perform the experiments. P. aeruginosa was routinely grown in Luria-Bertani medium $(1 \% \mathrm{w} / \mathrm{v} \mathrm{NaCl}, 1 \% \mathrm{w} / \mathrm{v}$ Tryptone, $0.5 \% \mathrm{w} / \mathrm{v}$ yeast extract) with shaking $(220 \mathrm{rpm})$ and cultured at $37^{\circ} \mathrm{C}$.

\subsection{Microwell dilution assay}

MIC values for $P$. aeruginosa were determinated by microwell dilution method following the protocol described by CLSI (2009) and Hanel and Raether (1998). The technique was carried out using pure, undiluted essential oils and different dilutions of extracts in 5\% DMSO (stock concentrations were $20 \mathrm{mg} / \mathrm{mL}$ and $30 \mathrm{mg} / \mathrm{mL}$ for F. macedonica and E. sibthorpiana, respectively). For detection of bacterial growth, a colorimetric viability assay was used (CLSI, 2009; Tsukatani et al. 2012). Obtained results were compared with positive control (solution of streptomycin in the concentration of $1 \mathrm{mg} / \mathrm{mL}$ ).

\subsection{Biofilm formation}

To determinate the influence of tested samples on biofilm formation of $P$. aeruginosa, the procedure of Drenkard and Ausubel (2002) and Spoering and Lewis (2001) with slight modifications was followed. This test was applied to investigate the ability of used extracts and essential oils to reduce/stop the biofilm formation in different sub-inhibitory concentrations (subMICs) $(0.125,0.25,0.5$ of MICs) which were determined in our previous studies (Mileski et al., 2014; 2015). The experiment was done in polystyrene flat-bottomed microtitre 96-well plates. In brief, $100 \mu \mathrm{L}$ of the medium (control) was pipetted into each well of the plates. Subsequently, $0.1 \mathrm{~mL}$ of subMICs of tested samples and $100 \mu \mathrm{L}$ of overnight culture inoculum was added. After $24 \mathrm{~h}$ of incubation at $37^{\circ} \mathrm{C}$, each well was washed twice with sterile PBS ( $\mathrm{pH} 7.4)$ and dried. Afterward, $0.1 \%$ of crystal violet was poured and left for 10 min with the aim to determine formed biofilm mass. After drying, $0.2 \mathrm{~mL}$ of $95 \%$ ethanol ( $\mathrm{v} / \mathrm{v})$ was added to solubilize the dye that had stained the biofilm cells. The excess stain was washed off with distilled water and left for $10 \mathrm{~min}$. After homogenization of the contents of the wells, the absorbance was read at $\lambda=625 \mathrm{~nm}$ on a Sunrise ${ }^{\mathrm{TM}}$-Tecan ELISA reader.

Biofilm formation values were calculated using formula:

$$
\text { Biofilm formation }[\%]=\frac{\text { mean }_{620} \text { control well }}{\text { mean } A_{620} \text { treated well }} \times 100 \%
$$

The experiment was done in triplicate. The values are presented as mean values \pm standard deviations.

\subsection{Twitching and flagella motility}

The cells of $P$. aeruginosa grown in the presence or the absence of 0.5 MICs of the extracts and essential oils were washed twice and re-suspended in sterile PBS to gain $1 \times 10^{8} \mathrm{CFU} / \mathrm{mL}$ (optical density (OD) of 0.1 at $660 \mathrm{~nm}$ ). The cells were stabbed into a nutrient agar plate with a sterile toothpick and incubated overnight at $37^{\circ} \mathrm{C}$ and later incubated at room temperature for $48 \mathrm{~h}$. The zone of the motility and the colony edges were observed and measured with a light microscope (Leika, 020-518.500 DM LS, Germany) (O'Toole and Kolter, 1998b;a). For testing flagella motility, all samples were mixed into 10
$\mathrm{mL}$ of molten $\mathrm{MH}$ and poured immediately over the surface of a solidified LB agar plate as an overlay. The plate was point inoculated with an overnight culture of PAO1 once the overlaid agar had solidified and incubated at $37^{\circ} \mathrm{C}$ for 3 days. The extent of swimming was determined by measuring the diameters of the colony in three different directions with square millimeter using graph paper (Yeo and Tham, 2012). The experiment was done in triplicate and the values are presented as a means \pm standard deviations.

\subsection{Pyocyanin production}

The flask assay was used for the quantification of the ability of tested samples $(0.5 \mathrm{MICs})$ to inhibit pyocyanin production in P. aeruginosa. An overnight culture of PAO1 was diluted to $\mathrm{OD}_{600}$ 0.2. SubMICs of the samples were added to $5 \mathrm{~mL}$ of bacterial inocula and the incubation lasted for $24 \mathrm{~h}$ at $37^{\circ} \mathrm{C}$. Thereafter, the treated cultures were extracted with $3 \mathrm{~mL}$ of chloroform, followed by mixing the chloroform layer with 1 $\mathrm{mL}$ of $0.2 \mathrm{M} \mathrm{HCl}$. The absorbance readings of the extracted organic layer were conducted at $\lambda=520 \mathrm{~nm}$ using a Shimadzu UV1601 spectrophotometer (Kyoto, Japan) (Yeo and Tham, 2012). The experiment was done in triplicate. The values are expressed as a ratio $\left(\mathrm{OD}_{520} / \mathrm{OD}_{600}\right) \times 100$.

\subsection{Statistical analysis}

The results of this study were analyzed using one-way analysis of variance (ANOVA) followed by Tukey's HSD test with $\mathrm{P}<0.05$ assumed as significant difference among mean values. This analysis was carried out using SPSS v. 18.0 program.

\section{RESULTS AND DISCUSSION}

\section{Anti-QS activity of extracts and essential oils}

The main goal of this study was to determinate the anti-QS activity of tested samples on P. aeruginosa PAO1. The results obtained in the analyses are given in Tables 2 and 3 and Figures 1-3. There is an increasing number of evidence that plants produce anti-QS compounds that interfere with intercellular signaling communication (Bauer and Mathesius, 2004; Teplitski et al., 2000). So far, several potential mechanisms of actions for anti-QS agents have been proposed, which are mainly based on interfering the QS system. They include inhibition of genetic regulatory system or biosynthesis of autoinductors, their inactivation or degradation and the reaction with signal receptors (Glamočlija et al., 2015). In recent years, the representatives of the Apiaceae family are also studied for QS inhibition in the bacteria. So far, only a few species were explored for QS potential (Khan et al., 2009; Sepahi et al., 2015) and this is the first data on F. macedonica and E. sibthorpiana activity against QS communication in P. aeruginosa. In our earlier investigations, the antibacterial potential of tested species and MIC values for P. aeruginosa were defined and the essential oils of E. sibthorpiana and F. macedonica showed to be the strongest anti-Pseudomonas agents among tested samples, in the range of streptomycin (MICs $=8.00-10.00 \mathrm{mg} / \mathrm{mL}$ and $1.50-12.00 \mathrm{mg} / \mathrm{mL}$ for extracts; MICs $=0.60 \mathrm{mg} / \mathrm{mL}$ and $0.34 \mathrm{mg} / \mathrm{mL}$ for essential oils of F. macedonica and E. sibthorpiana, respectively) (Mileski et al., 2014; 2015). According to presented results, it was observed that QS profiles of used samples differed significantly and used subMICs exhibited inhibitory activity on PAO1 determinants in varying quantity. Thus, comparative analysis of the results obtained in twitching and flagella test showed that in the presence of some samples, $P$. aeruginosa colonies were altered and the flagella appearance and diameters were affected. Control colony of this bacterium grew rapidly due to the ability of the cells to move using flagella with regular size, creating a wide zone of $12.00 \mathrm{~mm}$ in diameter, with rough, uneven and irregular edges. Bacterial 
Table 2. Effect of Ferulago macedonica and Echinophora sibthorpiana extracts and essential oils on PAO1 twitching and flagella motility.

\begin{tabular}{|c|c|c|c|c|c|}
\hline Extract/Standard & Plant part & $\begin{array}{c}\text { Colony } \\
\text { diameter }^{\mathrm{a}} \\
{[\mathrm{mm}]}\end{array}$ & $\begin{array}{r}\text { Flagella } \\
\text { diameter } \\
{[\mu \mathrm{m}]}\end{array}$ & Colony color & Colony edge \\
\hline \multicolumn{6}{|l|}{ F. macedonica } \\
\hline \multirow[t]{2}{*}{ Methanolic } & Inflorescence & $14.33 \pm 1.15 c$ & - & Light green & - \\
\hline & Aerial parts & $10.33 \pm 2.08 \mathrm{ab}$ & $64-160$ & Transparent white & $\begin{array}{r}\text { Sporadical } \\
\text { flagella }\end{array}$ \\
\hline \multirow[t]{2}{*}{ Ethanolic } & Inflorescence & $13.66 \pm 1.53 \mathrm{~b}$ & $40-240$ & Pale brown & Regular flagella \\
\hline & Aerial parts & $15.33 \pm 1.53 c$ & $80-240$ & Transparent white & Regular flagella \\
\hline \multirow[t]{2}{*}{ Aqueous } & Inflorescence & $14.66 \pm 0.58 c$ & $40-160$ & Whitish & Reduced flagella \\
\hline & Aerial parts & $16.33 \pm 1.00 \mathrm{c}$ & $40-160$ & Pale brown & Regular flagella \\
\hline Ess. oil & Aerial parts & $7.33 \pm 2.08 \mathrm{a}$ & $16-40$ & Whitish & Rare flagella \\
\hline \multicolumn{6}{|l|}{ E. sibthorpiana } \\
\hline Methanolic & Aerial parts & $14.00 \pm 4.58 c$ & $32-120$ & White & Rare flagella \\
\hline \multirow[t]{2}{*}{ Ethanolic } & Aerial parts & $15.33 \pm 1.53 c$ & $40-120$ & Whitish & Rare flagella \\
\hline & Roots & $14.00 \pm 0.00 \mathrm{c}$ & $80-160$ & Pale brown & Regular flagella \\
\hline \multirow[t]{2}{*}{ Aqueous } & Aerial parts & $15.66 \pm 0.58 c$ & $56-136$ & Whitish & Reduced flagella \\
\hline & Roots & $14.00 \pm 1.00 \mathrm{c}$ & $40-120$ & Pale brown & Reduced flagella \\
\hline Ess. oil & Aerial parts & $6.67 \pm 0.51 \mathrm{a}$ & - & Whitish & - \\
\hline Streptomycin & & $11.00 \pm 1.00 \mathrm{~b}$ & $24-56$ & Green & Tiny flagella \\
\hline Ampicillin & & $13.33 \pm 5.03 \mathrm{bc}$ & $16-56$ & Green & Regular flagella \\
\hline Control $\left(10^{9} \mathrm{CFU} / \mathrm{mL}\right)$ & & $12.00 \pm 1.00 \mathrm{~b}$ & $56-80$ & Light green & Regular flagella \\
\hline
\end{tabular}

${ }^{a}$ Values with different indicated letters in the same column mean significant difference $(\mathrm{P}<0.05)$.

cells formed thin layers with regular surface and blurred, unclear zones around green colony (Figures 1 and 2). According to the results, the samples reduced the movement of the cells and the growth of the colonies. As it can be seen in Table 2, the colors of $P$. aeruginosa treated with $F$. macedonica extracts and essential oil differed from transparent white to pale brown. Regarding F. macedonica, the best reduction of all parameters in this assay showed the essential oil of aerial parts in which presence the colony diameter was $7.33 \mathrm{~mm}$ (Table 2 and Figure 1). Moreover, it has been shown that both, essential oil and methanol extract of inflorescence had stronger activity in comparison to ampicillin (small diameters, absence of flagella), while methanol extract of aerial parts showed better activity than streptomycin. In this examination, the extracts and essential oil of E. sibthorpiana showed the following results: the color of the colonies ranged from transparent white, through whitish to pale brown (Table 2). The diameters of the colonies that grew in the presence of E. sibthorpiana extracts were greater in comparison to the control (14.00-15.66 $\mathrm{mm}$ and $12.00 \mathrm{~mm}$, respectively) and colonies with antibiotics (11.00-13.00 mm). The essential oil of E. sibthorpiana aerial parts showed the best activity on all used parameters (Table 2 , Figure 2). Thus, in the presence of the oil, the diameter of the whitish colony was $6.67 \mathrm{~mm}$ and flagella were not detected. It can be concluded that only essential oil of this species showed stronger activity than synthetic antibiotics. In this assay, few extracts did not show inhibitory effect on $P$. aeruginosa motility since the color and appearance of the colonies and flagella remained unchanged (Table 2; Figures 1 and 2).

The effects of used extracts and essential oils on PAO1 biofilm formation are presented in Table 3. Samples were tested at concentrations of $0.5,0.25$ and 0.125 of MICs. In general, anti-biofilm activity of E. sibthorpiana was more notable than of F. macedonica. The results given in Table 3 indicate low activity or complete absence of the effect of some $F$. macedonica samples in the reduction of biofilm formation. The extent of reducing ability ranged from $2.93 \%$ for $0.125 \mathrm{MIC}$ of aerial part aqueous extract to $28.22 \%$ for $0.5 \mathrm{MIC}$ of $F$. macedonica essential oil. The best activity among extracts showed $0.25 \mathrm{MIC}$ of ethanol extract of the inflorescence. On the other hand, both methanol extracts did not exhibit effectiveness in suppressing of biofilm formation. It can be concluded that streptomycin and ampicillin had stronger activity than extracts and essential oil of this species (Table 3). According to the results obtained for E. sibthorpiana, only methanol and aqueous extracts of roots showed activity at all tested concentrations (Table 3). The largest reduction of biofilm production was measured in the presence of $0.5 \mathrm{MIC}$ of root methanol extract (59.65\%), while 0.125 MIC of this sample reduced only $0.29 \%$ of its synthesis. In comparison with streptomycin and ampicillin, only methanol extract of the roots had stronger effect on biofilm (0.5 MIC), while ethanol extracts did not inhibit the biofilm synthesis (Table 3 ).

The reducing effects of tested agents on pyocyanin production were monitored by colorimetric test and it was conducted through comparison of the intensity of green coloration of the samples and control. The applied amounts of extracts and essential oils were sufficient to reduce the concentration of synthesized pigment and recorded inhibitory capacities of analyzed species in this assay were the most prominent (Figure 3). According to the results, essential oil of F. macedonica showed the strongest inhibition of pyocyanin synthesis (5.22\%), followed by E. sibthorpiana oil (10.69\%). Among extracts, the most effective were ethanol extract of E. sibthorpiana roots $(14.11 \%)$ and of $F$. macedonica aerial parts (19.05\%), which were significantly lower concentrations of synthesized pigment in comparison to the control $(141.55 \%)$. SubMICs of $F$. macedonica showed much higher activity in the reduction of pigment's production than in biofilm synthesis. The best $F$. macedonica extract in inhibition of pyocyanin production was ethanol extract of aerial parts (19.05\%). The highest measured concentration of the pigment was with methanol extract of aerial parts $(68.6 \%)$ which was still lower amount than in the presence of streptomycin and ampicillin $(84.27 \%$ and $97.59 \%$, respectively). In addition, all tested E. sibthorpiana samples significantly reduced the synthesis of pyocyanin and based on the reduction level it can be concluded that E. sibthorpiana showed strong anti-pyocyanin activity. The essential oil of 
Table 3. Effect of Ferulago macedonica and Echinophora sibthorpiana extracts and essential oils on PAO1 biofilm formation

\begin{tabular}{|c|c|c|c|c|}
\hline Extract/Standard & Plant part & $\begin{array}{r}0.5 \mathrm{MIC}^{\mathrm{a}, \mathrm{b}} \\
{[\%]}\end{array}$ & $\begin{array}{r}0.25 \mathrm{MIC} \\
{[\%]}\end{array}$ & $\begin{array}{r}0.125 \mathrm{MIC} \\
{[\%]}\end{array}$ \\
\hline \multicolumn{5}{|l|}{ F. macedonica } \\
\hline \multirow[t]{2}{*}{ Methanolic } & Inflorescence & n.i. & n.i. & n.i. \\
\hline & Aerial parts & n.i. & n.i. & n.i. \\
\hline \multirow[t]{2}{*}{ Ethanolic } & Inflorescence & n.i. & n.i. & $86.70 \pm 0.00 b$ \\
\hline & Aerial parts & n.i. & $96.18 \pm 0.78 b$ & $81.60 \pm 1.18 \mathrm{a}$ \\
\hline \multirow[t]{2}{*}{ Aqueous } & Inflorescence & n.i. & $76.17 \pm 1.21 \mathrm{ab}$ & $80.41 \pm 0.95 a$ \\
\hline & Aerial parts & n.i. & n.i. & $97.07 \pm 0.53 b$ \\
\hline Ess. Oil & Aerial parts & $71.78 \pm 2.04 \mathrm{~b}$ & $87.72 \pm 1.08 \mathrm{~b}$ & n.i. \\
\hline \multicolumn{5}{|l|}{ E. sibthorpiana } \\
\hline \multirow[t]{2}{*}{ Methanolic } & Aerial parts & $75.15 \pm 1.35 b$ & n.i. & n.i. \\
\hline & Roots & $40.35 \pm 2.51 \mathrm{a}$ & $66.52 \pm 2.03 \mathrm{a}$ & $99.71 \pm 0.82 b$ \\
\hline \multirow[t]{2}{*}{ Ethanolic } & Aerial parts & n.i. & n.i. & n.i. \\
\hline & Roots & n.i. & n.i. & n.i. \\
\hline \multirow[t]{2}{*}{ Aqueous } & Aerial parts & $92.11 \pm 0.88 b$ & n.i. & n.i. \\
\hline & Roots & $86.84 \pm 1.65 b$ & $71.05 \pm 1.72 \mathrm{a}$ & $77.37 \pm 1.45 \mathrm{a}$ \\
\hline Ess. Oil & Aerial parts & n.i. & n.i. & $68.42 \pm 2.20 \mathrm{a}$ \\
\hline Streptomycin & & $69.16 \pm 0.65 b$ & $56.46 \pm 0.46 a$ & $92.16 \pm 0.37 b$ \\
\hline Ampicillin & & $49.40 \pm 0.46 \mathrm{a}$ & $70.97 \pm 0.36 \mathrm{a}$ & $88.36 \pm 0.42 b$ \\
\hline
\end{tabular}

${ }^{a}$ The values are presented as mean values \pm standard deviations; n.i. - not identified.

${ }^{b}$ Values with different indicated letters in the same column mean significant difference $(\mathrm{P}<0.05)$.
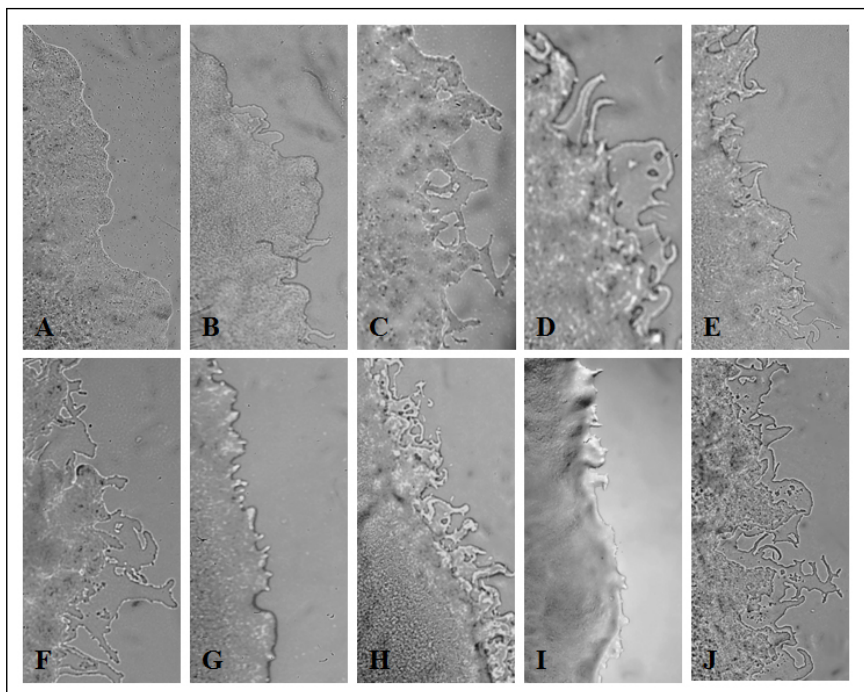

Fig. 1. Light microscopy of colony edges of PAO1 in twitching motility, grown in the presence or absence of Ferulago macedonica extracts, essential oil and antibiotics. The bacterial colonies grown with the presence of $0.5 \mathrm{MIC}$ of extracts (A-F) and essential oil (G); Pseudomonas aeruginosa colony in the presence of streptomycin had reduced protrusion $(\mathbf{H})$; colony in the presence of ampicillin with regularly formed protrusions (I); control Pseudomonas aeruginosa produced a flat, widely spread, irregularly shaped colony (J); Magnification: $(\mathbf{A}-\mathbf{J}) \times 100$.

this species had the highest potency reducing $130.86 \%$ of its production and all E. sibthorpiana extracts were more effective $(10.69 \%-35.22 \%)$ than used controls in this test (Figure 3).

In summary, the lowest activity of studied species was recorded in anti-biofilm assay where ethanol and methanol extracts of both species and essential oil of E. sibthorpiana did not show potential for reduction of biofilm synthesis. In contrast, analyzed samples showed the best activity in anti-pyocyanin test, which further enhanced their inhibitory effects on QS mechanism.

Previously, it was published that essential oil of aerial parts of Ferula asafoetida (Apiaceae) was active against used virulent factors of $P$. aeruginosa, while essential oil of Dorema aucheri

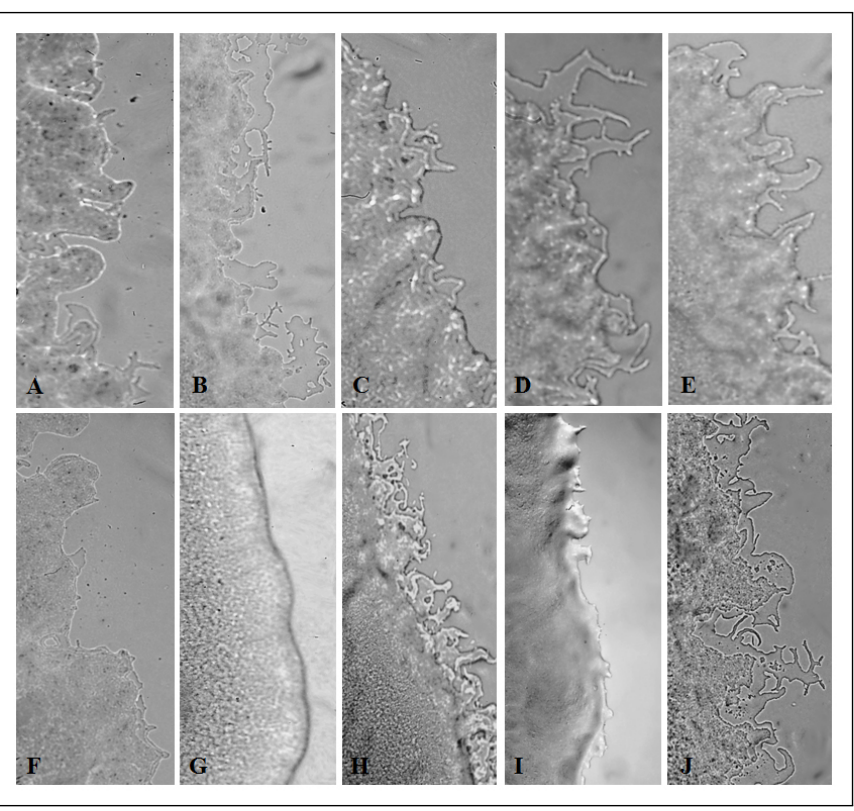

Fig. 2. Light microscopy of colony edges of PAO1 in twitching motility, grown in the presence or absence of Echinophora sibthorpiana extracts, essential oil and antibiotics. The bacterial colonies grown with the presence of $0.5 \mathrm{MIC}$ of extracts (A-F) and essential oil (G); Pseudomonas aeruginosa colony in the presence of streptomycin had reduced protrusion $(\mathbf{H})$; colony in the presence of ampicillin with regularly formed protrusions (I); control Pseudomonas aeruginosa produced a flat, widely spread, irregularly shaped colony (J); Magnification: $(\mathbf{A}-\mathbf{J}) \times 100$.

did not effect biofilm and pyocyanin synthesis (Sepahi et al., 2015). As previously mentioned, E. sibthorpina essential oil did not show potential in the reduction of biofilm synthesis, while F. macedonica oil expressed low activity. In our work, the anti-QS effects of tested extracts varied against different virulent factors, which is in agreement with the study of Adonizio (2008) where various plant extracts had different activity on $P$. aeruginosa. This bacterium uses the ability to form a biofilm controlled by gene expression, as a resistance to the antibiotics and as a protection from the host's immune 


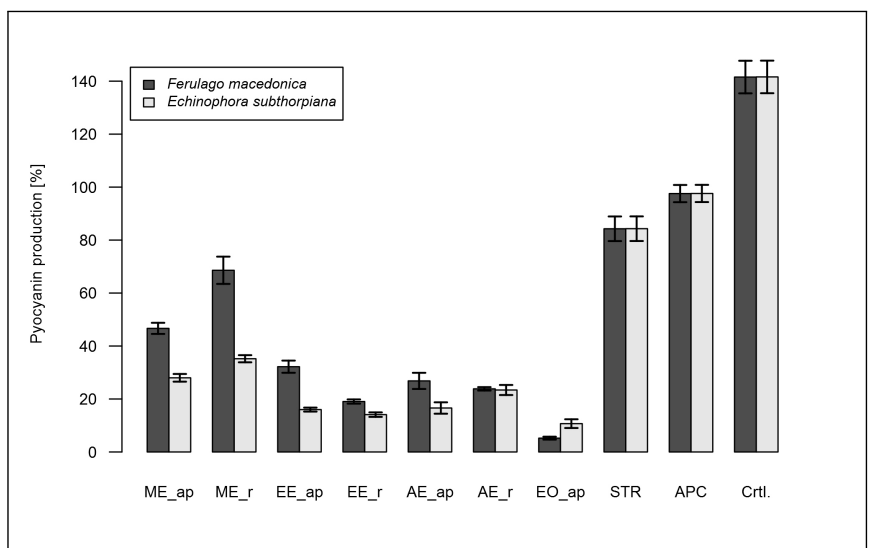

Fig. 3. Reduction of pyocyanin production of PAO1 by subMIC of Ferulago macedonica and Echinophora sibthorpiana samples and antibiotics; ME_ap - methanolic extract aerial part; ME_r - methanolic extract root; EE_ap - ethanolic extract aerial part; EE_r - methanolic extract root; AE_ap - methanolic extract aerial part; AE_r -methanolic extract root; EO_ap - essential oil aerial part; STR - Streptomycin; APC - Ampicillin; Crtl. - Control PAO1.

system. Anti-biofilm test applied in this study detects the inhibition of initial phase of biofilm formation (Soković et al., 2014) and according to obtained results, our samples demonstrated activity in a dosage-dependent manner. Tested essential oils in this study showed strong inhibition of the cells motility and the growth of the colonies. On the other hand, essential oils of Apium graveolens, Foeniculum vulgare, Petroselinum crispum and Trachyspermum ammi (Apiaceae) did not show anti-QS potential on C. violaceum CV12472 and CVO26 strains (Khan et al., 2009). Obtained differences in the activity of the samples recorded for anti-biofilm and anti-pyocyanin tests may originate from to the complex chemical composition of the extracts and essential oils and the possible synergism of various components (Adonizio, 2008). According to presented data in this work, ethanol extracts of E. sibthorpiana roots had moderate anti-QS activity and similar results were observed by Nagy (2010) for Eryngium aquaticum and Foeniculum vulgare root ethanol extracts. Aqueous extracts of both species tested in this study had lower anti-QS potential. These results may suggest a different polarity of ingredients active in the reduction of PAO1 virulence. The method used for extracts preparation and essential oils isolation also should be taken into consideration in results discussion (Adonizio, 2008).

\section{CONCLUSION}

In this work, tested concentrations of extracts and essential oils of F. macedonica and E. sibthorpiana were mostly sufficient to exhibit an inhibitory effect on selected $P$. aeruginosa determinants. In general, it can be concluded that extracts and oil of $E$. sibthorpiana had higher anti-QS potential. The most prominent were the effects of the samples in inhibition of pyocyanin synthesis, where the strongest were essential oils of both species. According to tested parameters of P. aeruginosa cells such as the colors and diameters of the colonies, the presence and diameters of flagella, the strongest tested agent was E. sibthorpiana oil. In contrast, used amounts of the samples showed low or lack of efficiency in suppressing of biofilm synthesis. All samples were more effective in anti-pyocyanin assay in comparison to the activity of streptomycin and ampicillin. In addition, few samples had stronger activity in twitching flagella test which supported their anti-QS properties considering intercellular communication of $P$. aeruginosa.

\section{ACKNOWLEDGMENTS}

Acknowledgment. The authors are grateful to the Ministry of Education, Science and Technological Development of the Republic of Serbia for financial support (Grants No. 173029 and 173021).

\section{REFERENCES}

Adonizio, A. L. (2008). Anti-quorum sensing agents from south Florida medicinal plants and their attenuation of Pseudomonas aeruginosa pathogenicity, ProQuest ETD Collection for FIU pp. 1-171.

Ahmad, V. U., Jassbi, A. R. and Pannahi, M. S. C. (1999). Analysis of the Essential Oil of Echinophora sibthorpiana Guss. by Means of GC, GC/MS and ${ }^{13}$ C-NMR Techniques, Journal of Essential Oil Research 11(1): 107-108.

Ali, A., Tabanca, N., Ozek, G., Ozek, T., Aytac, Z., Bernier, U. R., Agramonte, N. M., Baser, K. H. C. and Khan, I. A. (2015). Essential Oils of Echinophora lamondiana (Apiales: Umbelliferae): A Relationship Between Chemical Profile and Biting Deterrence and Larvicidal Activity Against Mosquitoes (Diptera: Culicidae), Journal of Medical Entomology 52(1): 93100.

Avijgan, M., Hafizi, M., Saadat, M. and Nilforoushzadeh, M. A. (2010). Antifungal Effect of Echinophora platyloba' s Extract against Candida albicans, Iranian Journal of Pharmaceutical Research 0(0): 285-289.

Avijgan, M., Mirzadeh, F. and Ahmadi Nia, E. (2012). The comparative study of anti-fungal effect of pharmaceutical products containing hydroalcoholic extract of Echinophora platyloba DC and flucona- zole in women with chronic recurrent vaginitis caused by candida albicans, Research Journal of Medical Sciences 17: S 103-S 107.

Baser, K. H., Erdemgil, F. Z. and Özek, T. (1994). Essential Oil of Echinophora tenuifolia L. subsp. sibthorpiana (Guss.) Tutin, Journal of Essential Oil Research 6(4): 399-400.

Baser, K. H., Kürkcüoglu, M., Malyer, H. and Bicakci, A. (1998). Essential Oils of Six Echinophora Species from Turkey, Journal of Essential Oil Research 10(3): 345-351.

Bauer, W. D. and Mathesius, U. (2004). Plant responses to bacterial quorum sensing signals, Current Opinion in Plant Biology 7(4): 429-433.

Cakilcioglu, U. and Turkoglu, I. (2010). An ethnobotanical survey of medicinal plants in Sivrice (Elazı̆̆-Turkey), Journal of Ethnopharmacology 132(1): 165-175.

Canonn, J. (1968). Ferulago W. Koch., in T. Tutin, V. Heywood, N. Burges, D. Moore, D. Valentine, S. Walters and D. Webb (eds), Flora Europaea, $2^{\text {nd }}$ edn, Cambridge University Press, London, UK, p. 359-360.

Cecchini, C., Coman, M. M., Cresci, A., Tirillini, B., Cristalli, G., Papa, F., Sagratini, G., Vittori, S. and Maggi, F. (2010). Essential oil from fruits and roots of Ferulago campestris (Besser) Grecescu (Apiaceae): composition and antioxidant and antiCandida activity, Flavour and Fragrance Journal 25(6): 493-502.

Değirmencioğlu, N., Gocmen, D., Dağdelen, A. and Dağdelen, F. (2005). Influence of Tarhana Herb (Echinophora sibthorpiana) on Fermentation of Tarhana, Turkish Traditional Fermented Food, Food Technology and Biotechnology 43: 175-179. 
Delaram, M., Kheiri, S. and Hodjati, M. R. (2011). Comparing the Effects of Echinophora-platyloba, Fennel and Placebo on Pre-menstrual Syndrome, Journal of Reproduction \& Infertility 12(3): 221-226.

Demirci, S. and Özkan, E. (2014). Ethnobotanical studies of some apiaceae plants in kahramanmaras and a review of their phytochemical studies, Journal of Faculty Pharmacy of Istanbul University 44(2): 241-250.

Drenkard, E. and Ausubel, F. M. (2002). Pseudomonas biofilm formation and antibiotic resistance are linked to phenotypic variation, Nature 416(6882): 740-743.

Eadie, M. (2004). The antiepileptic Materia Medica of Pediacus Dioscorides, Journal of Clinical Neuroscience 11(7): 697-701.

Entezari, M., Hashemi, M., Ashki, M., Ebrahimian, S., Bayat, M., Saraji, A. and Rohani, S. (2009). Studying the effect Echinophora platyloba extract on bacteria (Staphilococus aureus and Pseudomonas aeroginosa) and fungi (Candidia albicans, Aspergilus flavus and Aspergilus niger) in vitro, World Journal of Medical Science 4: 89-90.

Evergetis, E., Michaelakis, A. and Haroutounian, S. A. (2013) Exploitation of Apiaceae family essential oils as potent biopesticides and rich source of phellandrenes, Industrial Crops and Products 41: 365-370.

Gholivand, M., Rahimi-Nasrabadi, M., Mehraban, E., Niasari, M. and Batooli, H. (2011). Determination of the chemical composition and in vitro antioxidant activities of essential oil and methanol extracts of Echinophora platyloba DC, Natural Product Research 25(17): 1585-1595.

Glamočlija, J., Ćirić, A., Nikolić, M., Fernandes, n., Barros, L., Calhelha, R. C., Ferreira, I. C., Soković, M. and van Griensven, L. J. (2015). Chemical characterization and biological activity of Chaga (Inonotus obliquus), a medicinal "mushroom", Journal of Ethnopharmacology 162: 323-332.

Gokbulut, I., Bilenler, T. and Karabulut, I. (2013). Determination of Chemical Composition, Total Phenolic, Antimicrobial, and Antioxidant Activities of Echinophora tenuifolia Essential Oil, International Journal of Food Properties 16(7): 14421451.

Gurbuz, O., Gocmen, D., Ozmen, N. and Dagdelen, F. (2010). Effects of yeast, fermentation time, and preservation methods on tarhana, Preparative Biochemistry and Biotechnology 40(4): 263-275.

Khalighi-Sigaroodi, F., Hadjiakhoondi, A., Shahverdi, A. R., Mozaffarian, V.-A. and Shafiee", A. (2005). "Chemical composition and antimicrobial activity of the essential oil of Ferulago bernardii Tomk. and M. Pimen", DARU Journal of Pharmaceutical Sciences 13(3): 100-104.

Khan, M., Zahin, M., Hasan, S., Husain, F. and Ahmad, I. (2009). Inhibition of quorum sensing regulated bacterial functions by plant essential oils with special reference to clove oil, Letters in Applied Microbiology 49(3): 354-360.

Micevski, K. (2005). Echinophora L., in V. Matevski (ed.), Flora of Republic of Macedonia, $6^{\text {th }}$ edn, Macedonian Academy of Sciences and Arts, Skopje, p. 1543-1544.

Mileski, K., Džamic, A., Ćirić, A., Grujić, S., Ristić, M., Matevski, V. and Marin, P. (2014). Radical scavenging and antimicrobial activity of essential oil and extracts of Echinophora sibthorpiana Guss. from Macedonia, Archives of Biological Sciences 66(1): 401-413.
Mileski, K., Džamic, A., Ćirić, A., Ristić, M., Grujić, S., Matevski, V. and Marin, P. (2015). Composition, antimicrobial and antioxidant properties of endemic species Ferulago macedonica Micevski \& E. Mayer, Records of Natural Products 9(2): 208-223.

O'Toole, G. A. and Kolter, R. (1998a). Initiation of biofilm formation in Pseudomonas fluorescens WCS365 proceeds via multiple, convergent signalling pathways: a genetic analysis, Molecular Microbiology 28(3): 449-461.

O'Toole, G. A. and Kolter, R. (1998b). Flagellar and twitching motility are necessary for Pseudomonas aeruginosa biofilm development, Molecular Microbiology 30(2): 295-304.

Ozdemir, S., Gocmen, D. and Yildirim Kumral, A. (2007). A Traditional Turkish Fermented Cereal Food: Tarhana, Food Reviews International 23(2): 107-121.

Ozkan, A. M. G., Demirci, B., Demirci, F. and Başer, K. H. C. (2008). Composition and Antimicrobial Activity of Essential Oil of Ferulago longistylis Boiss. Fruits, Journal of Essential Oil Research 20(6): 569-573.

Ph.Eur.8.0. (2013). European Pharmacopoeia 8.0, Council of Europe, Strasbourg.

Razavi, S. M., Ravansalar, A. and Mirinejad, S. (2015). The investigation on phytochemicals from Ferulago angulata (Schlecht) Boiss, indigenous to central parts of Iran, Natural Product Research 29(21): 2037-2040.

Ruberto, G., Cannizzo, S., Amico, V., Bizzini, M. and Piattelli, M. (1994). Chemical Constituents of Ferulago nodosa, Journal of Natural Products 57(12): 1731-1733.

Saei-Dehkordi, S. S., Fallah, A. A., Saei-Dehkordi, S. S. and Kousha, S. (2012). Chemical Composition and Antioxidative Activity of Echinophora platyloba DC. Essential Oil, and Its Interaction with Natural Antimicrobials against Food-Borne Pathogens and Spoilage Organisms, Journal of Food Science 77(11): M631-M637.

Sepahi, E., Tarighi, S., Ahmadi, F. S. and Bagheri, A. (2015). Inhibition of quorum sensing in Pseudomonas aeruginosa by two herbal essential oils from Apiaceae family, Journal of Microbiology 53(2): 176-180.

Sharafati-chaleshtori, R., Rafieian-kopaei, M., Mortezaei, S., Sharafati-chaleshtori, A. and Amini, E. (2012). Antioxidant and antibacterial activity of the extracts of Echinophora platyloba D.C, African Journal of Pharmacy and Pharmacology 6: 2692-2695.

Soković, M., Ćirić, A., Glamočlija, J., Nikolić, M. and van Griensven, L. (2014). Agaricus Blazei Hot Water Extract Shows Anti Quorum Sensing Activity in the Nosocomial Human Pathogen Pseudomonas aeruginosa, Molecules 19(4): 4189-4199.

Spoering, A. L. and Lewis, K. (2001). Biofilms and Planktonic Cells of Pseudomonas aeruginosa Have Similar Resistance to Killing by Antimicrobials, Journal of Bacteriology 183(23): 6746-6751.

Taran, M., Reza Ghasempour, H. and Ebrahim, S. (2010). Antimicrobial activity of essential oils of Ferulago angulata subsp. carduchorum, Jundishapur Journal of Microbiology 3.

Teplitski, M., Robinson, J. B. and Bauer, W. D. (2000). Plants Secrete Substances That Mimic Bacterial N -Acyl Homoserine Lactone Signal Activities and Affect Population DensityDependent Behaviors in Associated Bacteria, Molecular Plant-Microbe Interactions 13(6): 637-648. 
Tutin, T. (1968). Echinophora L., in T. Tutin, V. Heywood, N. Burges, D. Moore, D. Valentine, S. Walters and D. Webb (eds), Flora Europaea, $2^{\text {nd }}$ edn, Cambridge University Press, London, UK, p. 324.

Valizadeh, H., Mahmoodi, F., Alizadeh, Z. and Bahadori, M. B. (2014). Isolation and Structure Elucidation of Secondary Metabolites from Echinophora platyloba DC from Iran, Journal of Medicinal Plants 13: 15-21.

Yeo, S. S. M. and Tham, F. Y. (2012). Anti-quorum sensing and antimicrobial activities of some traditional Chinese medicinal plants commonly used in South-East Asia, Malaysian Journal of Microbiology 8(1): 11-20.

Youse, H. A., Kazemian, A., Sereshti, M., Rahmanikhoh, E., Ahmadinia, E., Rafaian, M., Maghsoodi, R. and Darani, H. Y. (2012). Effect of Echinophora platyloba, Stachys lavandulifolia, and Eucalyptus camaldulensis plants on Trichomonas vaginalis growth in vitro, Advanced Biomedical Research 1: 79. 